\title{
Lutetium Lu-177 PSMA-R2
}

National Cancer Institute

\section{Source}

National Cancer Institute. Lutetium Lu-177 PSMA-R2. NCI Thesaurus. Code C150467.

A radioconjug ate composed of PSMA-R2, a human prostate-specific membrane antigen (PSMA)-targeting ligand, conjug ated to the beta-emitting radioisotope lutetium Lu 177 (177Lu), with potential antineoplastic activity against PSMA-expressing tumor cells. Upon intravenous administration of 177Lu-PSMA-R2, the PSMA-R2 moiety targets and binds to PSMA-expressing tumor cells. Upon binding, PSMA-expressing tumor cells are destroyed by 177 Lu through the specific delivery of beta particle radiation. PSMA, a tumor-associated antigen (TAA) and type II transmembrane protein, is expressed on the membrane of prostatic epithelial cells and overexpressed on the majority of prostate tumor cells. 